\title{
Effects of omeprazole or pantoprazole on platelet function in non-ST-segment elevation acute coronary syndrome patients receiving clopidogrel
}

\author{
Ruo-Xi Gu, Xiao-Zeng Wang*, Jing Li, Jie Deng, Xing-Xing Li and Jiao Wang
}

\begin{abstract}
Background: This study evaluated the effect of omeprazole or pantoprazole on platelet reactivity in non-STsegment elevation acute coronary syndrome (NSTE-ACS) patients receiving clopidogrel.

Methods: Consecutive patients with NSTE-ACS $(n=620)$ from general hospital of Shenyang Military Command were randomized to the omeprazole or pantoprazole $(20 \mathrm{mg} / \mathrm{d})$ group $(1: 1)$, and received routine dual antiplatelet treatment. Patients' reversion rate of adenosine diphosphate-induced platelet aggregation (ADP-PA) was assessed at baseline, 12 to $24 \mathrm{~h}$ after administration of medication, and after $72 \mathrm{~h}$ of percutaneous coronary intervention (PCl). The primary endpoint of the study was platelet reactivity assessed with ADP-PA at 30 days after PCI. Adverse events (AEs) were recorded for 30-day and 180-day follow-up periods.

Results: There were no significant differences between both the groups in platelet response to clopidogrel at 12-24 $\mathrm{h}$ after drug administration $(54.09 \% \pm 18.90 \%$ vs $51.62 \% \pm 19.85 \%, P=0.12), 72 \mathrm{~h}$ after $\mathrm{PCl}(52.15 \% \pm 19.45 \%$ vs $49.66 \% \pm$ $20.05 \%, P=0.18)$, and 30 days after $\mathrm{PCI}(50.44 \% \pm 14.54 \%$ vs $48.52 \% \pm 15.08 \%, P=0.17)$. The rate of AEs did not differ significantly between groups during the 30 -day $(15.2 \%$ vs $14.8 \%, P=0.91)$ and 180 -day $(16.5 \%$ vs $14.5 \%, P=0.50)$ follow-up periods after $\mathrm{PCl}$.

Conclusions: The addition of omeprazole or pantoprazole to clopidogrel did not restrict the effect of platelet aggregation by reducing the conversion of clopidogrel. Compared with clopidogrel alone, pantoprazole-clopidogrel and omeprazole-clopidogrel combinations did not increase the incidence of adverse clinical events during 30-day and 180-day follow-up periods after PCI.
\end{abstract}

Trial registration: The study is registered in the National Institutes of Health website with identifier NCT01735227. Registered 14 November 2012.

Keywords: Omeprazole, Pantoprazole, Clopidogrel, Platelet response, Non-ST-segment elevation acute coronary syndrome

\footnotetext{
* Correspondence: wxiaozeng@163.com

Department of Cardiology, General Hospital of Shenyang Military Region,

Shenyang 110840, China
} 


\section{Background}

Numerous clinical trials and physician practices have shown dual antiplatelet therapy (DAPT) to play a vital role in the treatment of patients with acute coronary syndrome (ACS) undergoing percutaneous coronary implantation (PCI) [1]. Although DAPT can effectively inhibit coronary stent thrombosis in patients with ischemic heart disease, reduce the incidence of major adverse cardiovascular events (MACE), and control the rate of readmission, thus greatly improving patients' quality of life, it can also increase the risk of gastrointestinal complications. Therefore, in 2010, the American College of Cardiology Foundation, the American College of Gastroenterology, and the American Heart Association recommended that proton pump inhibitors (PPIs) be prescribed to patients undergoing DAPT to decrease the risk of gastrointestinal bleeding [2-5]. However, medications metabolized by cytochrome P450 (CYP450), such as PPIs, have been shown to decrease the effectiveness of clopidogrel, and observational studies have suggested that PPIs might restrict the effect of platelet aggregation by reducing the conversion of clopidogrel into its active form through competitive inhibition of the CYP2C19 isoenzyme, based on pharmacodynamic data. In addition, several reports have shown that concomitant use of clopidogrel and PPIs is associated with an increased risk of adverse outcomes compared with the use of clopidogrel alone [6-10]. However, Dunn et al. [11] showed no significant difference in the number of adverse events (AEs) following PCI in patients with and without PPI. While omeprazole has been associated with reduced clopidogrel efficacy, as assessed by the platelet reactivity index vasoactive stimulated phosphoprotein, new PPIs such as pantoprazole and esomeprazole have been shown to have no effect on biological response to clopidogrel [12]. Because many PPIs are metabolized to varying degrees by CYP2C19, the reported negative omeprazole-clopidogrel drug interaction may not be caused by a class effect $[13,14]$.

PPIs are usually prescribed to patients undergoing dual antiplatelet therapy to decrease the risk of gastrointestinal bleeding. However, there has been an increased incidence of MACE because of the interaction of PPIs and clopidogrel. Therefore, this study was conducted to evaluate the effect of omeprazole or pantoprazole on platelet reactivity in non-ST-segment elevation acute coronary syndrome (NSTE-ACS) patients receiving clopidogrel.

\section{Methods}

\section{Study design and population}

This prospective, randomized controlled clinical trial (NCT01735227) was conducted at department of cardiology, General Hospital of Shenyang Military Region to compare the influence of omeprazole or pantoprazole on the antiplatelet effect of clopidogrel in patients undergoing
PCI for NSTE-ACS. In our study, we defined NSTE-ACS as unstable angina (UA) and NSTEMI because all STEMI patients received immediate emergency PCI if the clinical symptoms were compatible with acute myocardial ischemia within $12 \mathrm{~h}$ before admission. Patients aged 18 to 75 years were eligible to be enrolled if they had coronary artery disease and opted to undergo PCI. Eligible patients were randomly assigned to 2 groups that received either omeprazole or pantoprazole (in a 1:1 ratio; random envelope provided by the CRO company). The major exclusion criteria included the use of glycoprotein IIb/IIIa inhibitors within $24 \mathrm{~h}$ before enrollment or use of cilostazol within 7 days before enrollment, contraindication to DAPT, and a history of severe systemic bleeding or greatly increased risk of bleeding. Patients were also excluded if they had New York Heart Association grade III or IV cardiac function, PCI or coronary artery bypass grafting (CABG) within the past year, persistent atrial fibrillation requiring long-term warfarin, or prior use of a PPI or clopidogrel. Patients with serious liver or kidney dysfunction were also excluded. The design of the study is depicted in Fig. 1.

For $80 \%$ power to detect the noninferiority of omeprazole-clopidogrel or pantoprazole-clopidogrel to clopidogrel alone, a sample size of 295 patients were assigned to each of the omeprazole and pantoprazole groups in a 1:1 ratio. Patients were required to achieve a two-sided significance level of 0.05 . Taking into account an attrition rate of about $5 \%-10 \%$, at least 620 patients were enrolled in our study.

\section{Study protocol}

The study was approved by the ethics committee of General Hospital of Shenyang Military Region. The study was performed in accordance with ethical principles that have their origin in the Declaration of Helsinki and are consistent with $\mathrm{ICH} /$ Good Clinical Practice. All patients provided written informed consent before enrollment. All patients received a loading dose of $300 \mathrm{mg}$ each of clopidogrel and aspirin, and were randomized to take $20 \mathrm{mg}$ daily of either omeprazole (Losec MUPS; AstraZeneca, London, UK) or pantoprazole (Tecta; Takeda Pharmaceuticals International GmbH, Konstanz, Germany) and received routine dual antiplatelet treatment (aspirin $300 \mathrm{mg}$ and clopidogrel $75 \mathrm{mg}$ daily). PPI therapy was resumed in both groups following completion of the primary endpoint of the study.

Blood samples (two $3.6 \mathrm{ml}$ tubes) were taken to measure the reversion rate of ADP-PA, which was defined as $20 \mu \mathrm{mol} / \mathrm{L}$ adenosine diphosphate-induced platelet aggregation by light transmittance aggregometry (LTA) before randomization, 12 to $24 \mathrm{~h}$ after drug administration, and $72 \mathrm{~h}$ after PCI. The upper, platelet-rich plasma layer was prepared by centrifuging blood samples for $12 \mathrm{~min}$; the remaining platelet-poor plasma was obtained 


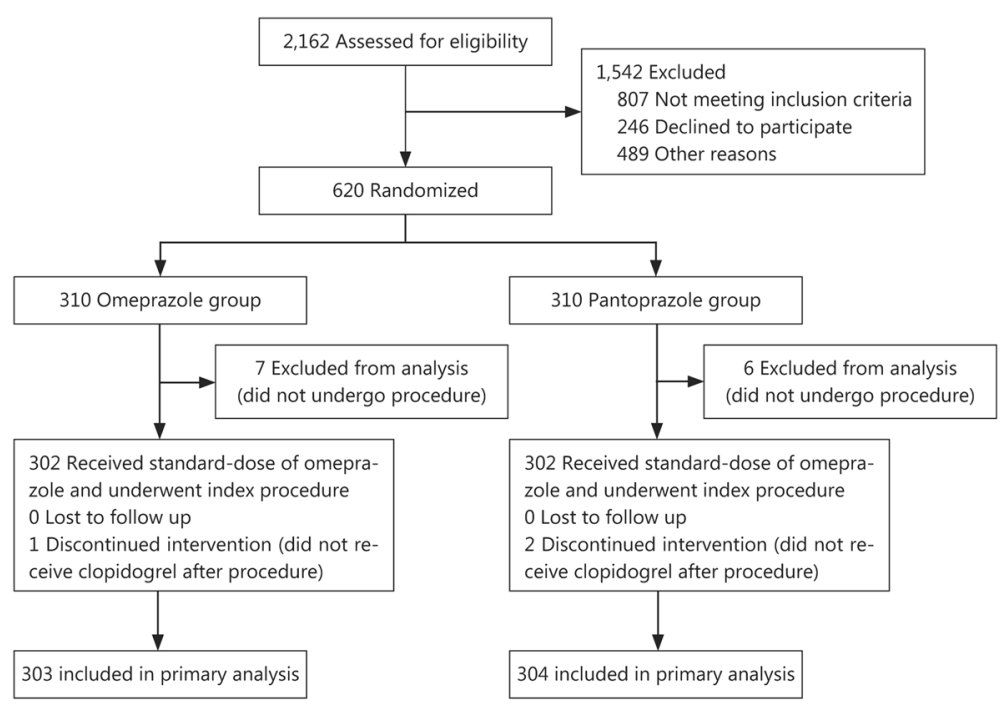

Fig. 1 Patient flowchart

by centrifuging for $15 \mathrm{~min}$ for use as a blank control. Platelet aggregation rate was determined with an $\mathrm{AggRAM}^{\circ}$ eight-channel Advanced Modular System for Platelet Aggregation Ristocetin Cofactor (Helena Laboratories, Beaumont, TX, USA) by a skilled technician. An assessment of platelet reactivity by LTA was scheduled for all enrolled patients 30 days after PCI. Results were used in the primary-endpoint evaluation.

\section{Study endpoints}

The primary endpoint of the study was platelet reactivity of $20 \mu \mathrm{mol} / \mathrm{L}$ ADP-PA by LTA 30 days after PCI. The secondary endpoints were clinical events during the 30day and 180-day follow-up periods after PCI, which included stent thrombosis, MACE (cardiac death, nonfatal myocardial infarction, or ischemic symptom-driven target-vessel revascularization [TVR] or non-TVR), allcause death, thrombolysis in myocardial infarction (TIMI) bleeding events, stroke, and adverse drug reactions. Stent thrombosis was defined according to the Academic Research Consortium criteria, and only definite stent thrombosis was counted [15]. Myocardial infarction was defined as a creatine kinase myocardial band level that was more than twice the upper limit of normal range and either symptoms consistent with acute myocardial infarction or electrocardiographic changes in at least two contiguous leads (pathologic Q waves 0.04 s in duration or persistent ST-segment elevation or ST-segment depression $>0.1 \mathrm{mV}$ ). TVR included intervention because of recurrence in any part of the original vessel. Bleeding events were divided into major or minor bleeding on the basis of thrombolysis in TIMI bleeding classification as follows: major bleeding = intracranial hemorrhage or a $>5 \mathrm{~g} / \mathrm{dl}$ decrease in hemoglobin concentration or a $>15 \%$ absolute decrease in hematocrit; moderate bleeding = observed blood loss ( $\mathrm{a}>4 \mathrm{~g} / \mathrm{dl}$ decrease in hemoglobin concentration or $\mathrm{a}>12 \%$ decrease in hematocrit); minor bleeding $=$ no observed blood loss $(\mathrm{a}>3 \mathrm{~g} / \mathrm{dl}$ decrease in hemoglobin concentration or a $>10 \%$ decrease in hematocrit) [16]. Stroke was defined as persistent loss of neurological function developing after primary PCI and an acute lesion identified with magnetic resonance imaging. Adverse drug reactions in our study included reactions to aspirin, clopidogrel, nitrates, and statins.

All patients had a follow-up evaluation at a clinic visit or via telephone contact 30 and 180 days following PCI. The China Cardiovascular Research Foundation (CCRF), an independent clinical research organization, was responsible for database management, safety monitoring, and evaluation of AEs. All AEs were adjudicated by a blinded, independent clinical-events committee. The CCRF reviewed the data periodically to identify any potential safety issues.

\section{Statistical analysis}

This study used intention-to-treat analysis data sets for statistical analysis. Comparisons among normally distributed continuous variables are presented as mean \pm standard deviation and were compared using Student's unpaired $t$-test. Categorical variables are expressed as frequencies and percentages. Comparisons between groups were made using the Chi-square or Fisher exact test for categorical variables and nonparametric statistical testing (MannWhitney $U$-test) for continuous variables. Values of $P<$ 0.05 were considered statistically significant. All analyses were performed with the IBM SPSS Statistics for Windows, Version 21.0 (IBM Corp, Armonk, NY, USA). 


\section{Results}

From October 2012 to September 2013, a total of 620 patients with NSTE-ACS were enrolled from general hospital of Shenyang military region. Thirteen patients did not undergo angiography and were excluded. The remaining 607 patients were included, with 303 patients allocated to the omeprazole group and 304 to the pantoprazole group. All patients completed 30 and 180 days follow-up periods after PCI. All groups were generally well balanced with regard to baseline demographic, clinical, and procedural characteristics. Baseline and procedural characteristics of the study patients are shown in Tables 1 and 2. Of those 607 patients, 602 (99.8\%) underwent coronary angiography after an oral loading dose of aspirin $300 \mathrm{mg}$ and clopidogrel $300 \mathrm{mg}$ on admission. Successful PCI, which was defined as recovery of coronary flow to TIMI grade 2 to 3 and residual stenosis $<50 \%$, was achieved in all patients. Two patients died during hospitalization: one from stent thrombosis and the other because of traumatic brain injury. There were no differences between the omeprazole and pantoprazole groups in platelet response to clopidogrel on admission, 12 to $24 \mathrm{~h}$ after drug administration, and $72 \mathrm{~h}$ and 30 days after PCI (Fig. 2).

There were no significant differences between the two groups in coronary angiography clinical data (Table 3), and the 30-day and 180-day follow-up rates were $100 \%$. During the 30-day follow-up period, there was one case of stent thrombosis in the pantoprazole group and none in the omeprazole group, but the difference was not significant. There were no significant between-group differences in rates of MACE. No major or minor bleeding occurred in either group, and the rates of minimal bleeding, which occurred in both groups, did not differ significantly between the groups. Although one patient died from traumatic brain injury in the omeprazole

Table 1 Baseline patient characteristics

\begin{tabular}{|c|c|c|c|}
\hline Characteristic & Omeprazole group $(n=303)$ & Pantoprazole group $(n=304)$ & $P$ value \\
\hline Age (year) & $59.15 \pm 8.75$ & $58.76 \pm 8.50$ & 0.58 \\
\hline Male $[n(\%)]$ & $209(69.0)$ & $215(70.7)$ & 0.66 \\
\hline \multicolumn{4}{|l|}{ Cardiovascular risk factors } \\
\hline BMI $\left(\mathrm{kg} / \mathrm{m}^{2}\right)$ & $25.57 \pm 3.86$ & $25.54 \pm 3.43$ & 0.92 \\
\hline Hypertension [n (\%)] & $199(65.7)$ & $186(61.2)$ & 0.27 \\
\hline Dyslipidemia [n (\%)] & $135(44.6)$ & $125(41.1)$ & 0.41 \\
\hline Diabetes mellitus [n (\%)] & $84(27.7)$ & $82(27.0)$ & 0.86 \\
\hline Active smoking $[n(\%)]$ & $170(56.1)$ & $171(56.3)$ & 1.00 \\
\hline Previous myocardial infarction [n (\%)] & $48(15.8)$ & $46(15.1)$ & 0.82 \\
\hline Previous transient ischemic attack/stroke $[n(\%)]$ & $27(8.9)$ & $27(8.9)$ & 1.00 \\
\hline \multicolumn{4}{|l|}{ Final clinical diagnosis [n (\%)] } \\
\hline UA & $262(84.3)$ & $264(86.8)$ & 0.90 \\
\hline NSTEMI & $42(13.9)$ & $39(12.8)$ & 0.72 \\
\hline \multicolumn{4}{|l|}{ Laboratory parameters } \\
\hline WBC $\left(\times 10^{12} / L\right)$ & $7.01 \pm 1.85$ & $6.91 \pm 1.74$ & 0.48 \\
\hline $\operatorname{RBC}\left(\times 10^{9} / L\right)$ & $6.04 \pm 0.34$ & $4.52 \pm 0.55$ & 0.32 \\
\hline $\operatorname{PLT}\left(\times 10^{12} / \mathrm{L}\right)$ & $211.16 \pm 51.24$ & $210.42 \pm 51.89$ & 0.86 \\
\hline $\mathrm{Hb}(\mathrm{g} / \mathrm{L})$ & $140.66 \pm 15.19$ & $141.24 \pm 13.87$ & 0.67 \\
\hline Creatinine (mg/dl) & $71.73 \pm 23.13$ & $69.77 \pm 22.95$ & 0.27 \\
\hline CRP $(\mathrm{mmol} / \mathrm{L})$ & $3.73 \pm 6.47$ & $4.82 \pm 17.54$ & 0.59 \\
\hline TNT (ng/ml) & $0.08 \pm 0.32$ & $0.07 \pm 0.31$ & 0.62 \\
\hline Blood glucose (mmol/L) & $6.40 \pm 2.46$ & $6.75 \pm 3.39$ & 0.21 \\
\hline Total cholesterol (mmol/L) & $3.88 \pm 1.05$ & $3.86 \pm 0.99$ & 0.82 \\
\hline Total triglycerides (mmol/L) & $1.97 \pm 1.32$ & $1.92 \pm 1.42$ & 0.95 \\
\hline Low-density lipoprotein cholesterol (mmol/L) & $2.18 \pm 0.95$ & $2.14 \pm 0.87$ & 0.56 \\
\hline High-density lipoprotein cholesterol (mmol/L) & $1.09 \pm 0.72$ & $1.11 \pm 0.80$ & 0.80 \\
\hline Baseline ADP-PA (\%) & $60.00 \pm 20.87$ & $57.50 \pm 19.73$ & 0.13 \\
\hline
\end{tabular}

BMI Body mass index, UA Unstable angina, NSTEMI Non-ST segment elevation myocardial infarction, WBC White blood cell, RBC Red blood cell, PLT Platelet, Hb Hemoglobin, CRP C-reactive protein, ADP-PA Adenosine diphosphate-induced platelet aggregation 
Table 2 Procedural characteristic during hospitalization

\begin{tabular}{|c|c|c|c|}
\hline Characteristic & Omeprazole group $(n=303)$ & Pantoprazole group $(n=304)$ & $P$ value \\
\hline Systolic blood pressure (mmHg) & $140.01 \pm 22.16$ & $138.86 \pm 18.36$ & 0.55 \\
\hline Diastolic blood pressure $(\mathrm{mmHg})$ & $79.81 \pm 13.88$ & $80.05 \pm 11.11$ & 0.84 \\
\hline Left ventricular ejection fraction (\%) & $62.5 \pm 11.2$ & $63.7 \pm 14.7$ & 0.30 \\
\hline \multicolumn{4}{|l|}{ Medications at discharge $[n(\%)]$} \\
\hline Statin & $297(98.0)$ & $299(98.4)$ & 0.77 \\
\hline ACE inhibitors & $160(53.0)$ & $143(47.0)$ & 0.17 \\
\hline Angiotensin receptor blocker & $86(28.4)$ & $93(30.7)$ & 0.59 \\
\hline Beta-blockers & $226(74.6)$ & $244(80.3)$ & 0.10 \\
\hline Calcium-channel blockers & $77(25.4)$ & $79(26.0)$ & 0.93 \\
\hline Nitrate & $274(90.4)$ & $268(88.2)$ & 0.43 \\
\hline Diuretics & $35(11.6)$ & $33(10.9)$ & 0.80 \\
\hline Glycoprotein IIb/IIla antagonists & $32(14.0)$ & $22(9.5)$ & 0.15 \\
\hline
\end{tabular}

group, there was no significant difference between the groups in all-cause death. No patient in either group experienced stroke. There was no significant difference in the rate of adverse drug reactions between the omeprazole and pantoprazole groups. AEs for the two groups during the 30-day follow-up period are shown in Table 4 and Fig. 3.

During the 180-day follow-up period, there was no stent thrombosis in either group. One major and three minor bleeding events occurred in the pantoprazole group, but there was no significant difference in the rate of minimal bleeding between the groups. There was no significant association of either intervention with all-cause death. One patient in the omeprazole group died of lung cancer and one patient in the pantoprazole group died of acute brainstem hemorrhage (Table 5 and Fig. 4).

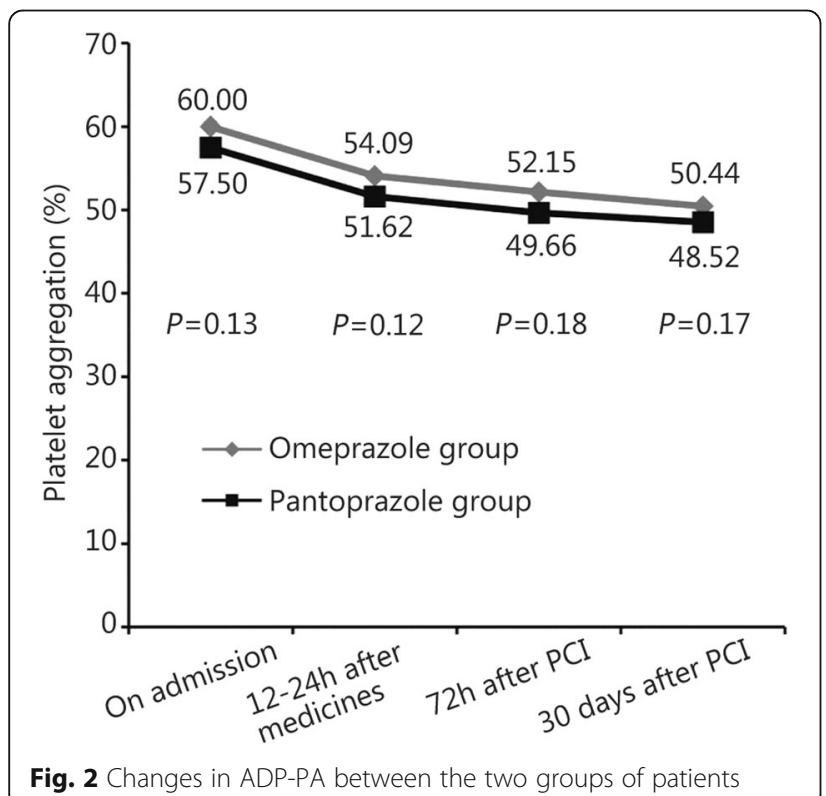

\section{Discussion}

Clopidogrel combined with aspirin in patients undergoing PCI has been recommended because of its ability to reduce cardiovascular events. It is well known that gastrointestinal hemorrhage is the most common serious bleeding complication of antiplatelet therapy, especially in ACS patients. Therefore, PPIs are often prescribed to prevent gastrointestinal tract bleeding during DAPT [17]. Recent studies, however, have suggested that PPIs might reduce the antiplatelet effect of clopidogrel through inhibition of hepatic CYP2C19 [18-20]. Clopidogrel is a prodrug that requires hepatic CYP450-dependent biotransformation into an active metabolite, which irreversibly blocks the P2Y12 ADP receptor $[21,22]$. The genotype of this enzyme has been divided into three groups: rapid extensive metabolizers, intermediate metabolizers, and poor metabolizers. There are genetically interethnic differences in the frequencies of poor metabolizers of CYP2C19: $2.5 \%$ in white Americans, $2.0 \%$ in African Americans, 3.5\% in white Europeans, and $19.8 \%$ in the Chinese-Han population. Because of the much greater prevalence of CYP2C19 loss-of-function alleles in Asians than in other populations, the influence of drug interaction might be more apparent in Asian people [23]. A nationwide population study to investigate the influences of concomitant use of clopidogrel and PPIs would be necessary to elucidate CYP2C19 polymorphisms. A Taiwanese population-based study has reported that the concomitant use of clopidogrel and PPIs is associated with an increased risk of rehospitalization and mortality in patients undergoing PCI. Thus, prior studies have suggested that an attenuation of the antiplatelet effect of clopidogrel by PPIs could lead to adverse clinical outcomes by decreasing the efficacy of clopidogrel. Previous reports have demonstrated that concomitant use of PPI and clopidogrel after PCI was associated with an increased risk of rehospitalization and mortality, and higher rates of 
Table 3 Analysis of coronary angiography

\begin{tabular}{|c|c|c|c|}
\hline Characteristic & Omeprazole group $(n=303)$ & Pantoprazole group $(n=304)$ & $P$ value \\
\hline \multicolumn{4}{|l|}{ Target coronary vessel $[n(\%)]$} \\
\hline Single-vessel & $84(29.2)$ & $94(32.3)$ & 0.42 \\
\hline Multivessel & $206(71.5)$ & $197(67.7)$ & 0.32 \\
\hline \multicolumn{4}{|l|}{ Localization of culprit lesion [n (\%)] } \\
\hline Left main coronary artery & $40(13.2)$ & $38(12.5)$ & 0.81 \\
\hline Left anterior descending artery & $219(72.3)$ & $225(74.0)$ & 0.65 \\
\hline Left circumflex artery & $142(46.9)$ & $135(44.4)$ & 0.57 \\
\hline Right coronary artery & $164(54.1)$ & $158(52.0)$ & 0.63 \\
\hline Other artery & $113(37.3)$ & $91(29.9)$ & 0.06 \\
\hline \multicolumn{4}{|l|}{ Baseline blood flow in the culprit vessel $[n(\%)]$} \\
\hline TIMI 0 & $47(15.7)$ & $35(11.6)$ & 0.16 \\
\hline TIMI 1 & $18(6.0)$ & $17(5.6)$ & 0.86 \\
\hline TIMI 2 & $33(11.0)$ & $27(8.9)$ & 0.42 \\
\hline TIMI 3 & $202(67.3)$ & $223(73.8)$ & 0.09 \\
\hline \multicolumn{4}{|l|}{ Final blood flow in the culprit vessel $[n(\%)]$} \\
\hline TIMI 0 & $8(2.7)$ & $11(3.6)$ & 0.64 \\
\hline TIMI 3 & $281(93.7)$ & $285(94.4)$ & 0.73 \\
\hline Characteristics of coronary angiography & & & 0.23 \\
\hline Number of implanted stents ( $n$ ) & $1.29 \pm 1.63$ & $1.18 \pm 1.07$ & 0.23 \\
\hline Average stent diameter (mm) & $2.24 \pm 1.42$ & $2.22 \pm 1.44$ & 0.81 \\
\hline Average length of implanted stents (mm) & $18.62 \pm 12.50$ & $18.55 \pm 12.98$ & 0.94 \\
\hline \multicolumn{4}{|l|}{ Contrast media $[n(\%)]$} \\
\hline Isotonic & $25(8.4)$ & $27(9.0)$ & 0.85 \\
\hline Non-isotonic & $274(91.6)$ & $273(91.0)$ & 0.85 \\
\hline Median contrast agent dose (ml) & $220.20 \pm 134.97$ & $205.73 \pm 118.83$ & 0.16 \\
\hline
\end{tabular}

Table 4 AEs during 30-day follow-up

\begin{tabular}{|c|c|c|c|}
\hline Characteristic & Omeprazole group $(n=303)$ & Pantoprazole group $(n=304)$ & $P$ value \\
\hline Stent thrombosis [n (\%)] & 0 & $1(0.3)$ & 1.00 \\
\hline MACEs $[n(\%)]$ & $7(2.3)$ & $5(1.6)$ & 0.58 \\
\hline Cardiac death & $1(0.3)$ & 0 & 0.50 \\
\hline Myocardial infarction & 0 & 0 & - \\
\hline Ischemic symptoms driven target vessel revascularization & $1(0.3)$ & 0 & 0.50 \\
\hline Non-target vessel revascularization & $5(1.7)$ & $5(1.6)$ & 1.00 \\
\hline Recurrent angina [n (\%)] & $19(6.3)$ & $12(3.9)$ & 0.20 \\
\hline All-cause death $[n(\%)]$ & $1(0.3)^{\mathrm{a}}$ & 0 & 0.50 \\
\hline \multicolumn{4}{|l|}{ TIMI bleeding events $[n(\%)]$} \\
\hline Major & 0 & 0 & - \\
\hline Moderate & 0 & 0 & - \\
\hline Minor & $4(1.3)$ & $8(2.6)$ & 0.38 \\
\hline Stroke $[n(\%)]$ & 0 & 0 & - \\
\hline Adverse drug reactions [n (\%)] & $23(7.6)$ & $29(9.5)$ & 0.47 \\
\hline AEs $[n(\%)]$ & $46(15.2)$ & $45(14.8)$ & 0.91 \\
\hline
\end{tabular}

${ }^{\mathrm{a}}$ One patient died due to brain injury in the omeprazole group 


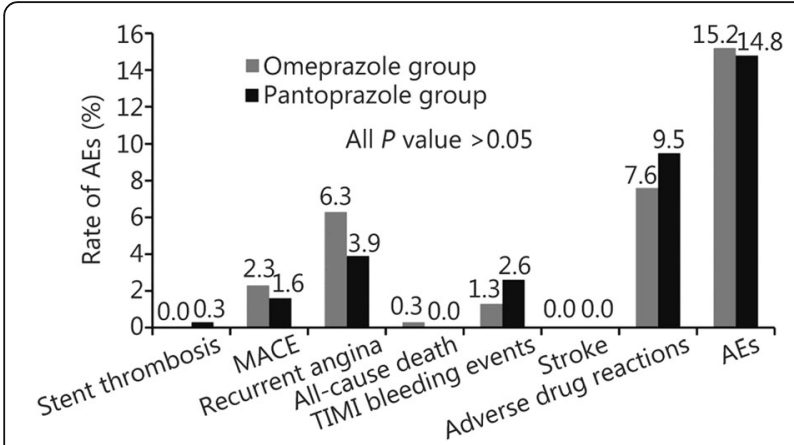

Fig. 3 The rate of adverse clinical events in the two groups during 30-day follow-up

cardiovascular events and increased risk of adverse outcomes have been shown in patients undergoing treatment with PPI-clopidogrel combination compared with clopidogrel alone [9].

In contrast, Ray et al. reported that concomitant use of clopidogrel with a PPI did not increase the incidence of serious cardiovascular disease but was associated with a $50 \%$ reduction in the incidence of hospitalizations for gastrointestinal bleeding. Several other studies have also reported that PPI use is not associated with an increased risk of cardiovascular events or mortality in patients taking clopidogrel $[3-10,12]$.

Table 5 AEs during 180-day follow-up

\begin{tabular}{|c|c|c|c|}
\hline Characteristic & $\begin{array}{l}\text { Omeprazole group } \\
(n=303)\end{array}$ & $\begin{array}{l}\text { Pantoprazole } \\
\text { group }(n=304)\end{array}$ & $P$ value \\
\hline Stent thrombosis $[n(\%)]$ & 0 & 0 & - \\
\hline MACEs $[n(\%)]$ & $8(2.6)$ & $7(2.3)$ & 0.80 \\
\hline Cardiac death & $1(0.3)$ & 0 & 0.50 \\
\hline Myocardial infarction & 0 & 0 & - \\
\hline $\begin{array}{l}\text { Ischemic symptoms } \\
\text { driven target vessel } \\
\text { revascularization }\end{array}$ & $3(1.0)$ & $1(0.3)$ & 0.37 \\
\hline $\begin{array}{l}\text { Non-target vessel } \\
\text { revascularization }\end{array}$ & $6(2.0)$ & $6(2.0)$ & 1.00 \\
\hline Recurrent angina $[n(\%)]$ & $30(9.9)$ & $24(7.9)$ & 0.40 \\
\hline All-cause death $[n(\%)]$ & $1(0.3)^{\mathrm{a}}$ & $1(0.3)^{b}$ & 1.00 \\
\hline $\begin{array}{l}\text { TIMI bleeding } \\
\text { evens }[n(\%)]\end{array}$ & $15(5.0)$ & $19(6.3)$ & 0.60 \\
\hline Major & 0 & $1(0.3)$ & 1.00 \\
\hline Moderate & 0 & $3(1.0)$ & 0.25 \\
\hline Minor & $16(5.3)$ & $14(4.6)$ & 0.71 \\
\hline Stroke $[n(\%)]$ & $1(0.3)$ & 0 & 0.50 \\
\hline $\begin{array}{l}\text { Adverse drug } \\
\text { reactions [n (\%)] }\end{array}$ & $17(5.6)$ & $19(6.3)$ & 0.86 \\
\hline AEs $[n(\%)]$ & $50(16.5)$ & $44(14.5)$ & 0.50 \\
\hline
\end{tabular}

${ }^{\mathrm{a}}$ One patient died due to lung cancer in the omeprazole group ${ }^{b}$ One patient died due to acute brainstem hemorrhage in the pantoprazole group

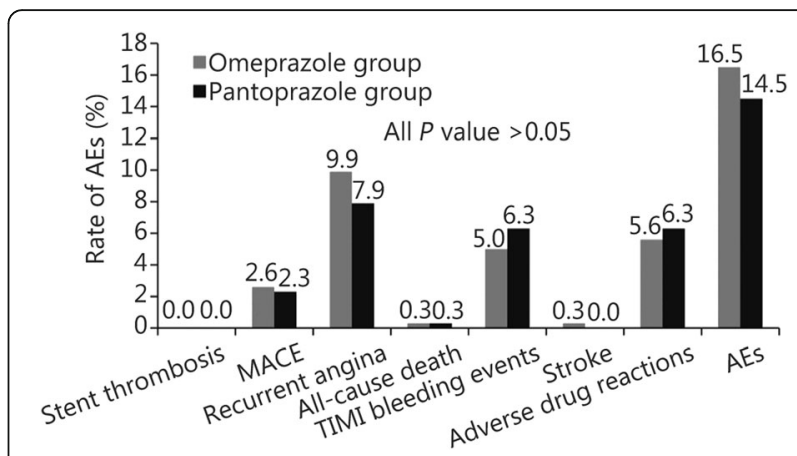

Fig. 4 The rate of AEs in both the groups during 180-day follow-up

Kwok et al. [24] reviewed 23 studies involving 93,278 patients, and their meta-analysis of 13 of these studies showed no significant association between PPI use and overall mortality. In the latest study, the COGENT trial, 3761 patients with an ACS were randomized at the time of PCI to take clopidogrel and omeprazole or clopidogrel alone, and no evidence of any adverse clinical interaction was observed [3]. The results showed that the majority of patients who were discharged on a PPI were prescribed lansoprazole $(77.7 \%)$, followed by omeprazole (17.8\%) and rabeprazole (4.5\%). Kenngott et al. [25] indicated that the clopidogrel-PPI interaction does not seem to be a PPI class effect, and that rabeprazole did not interfere with the clopidogrel effect in a subject with a clear omeprazole-clopidogrel interaction. Other studies have suggested that the omeprazole-clopidogrel interaction was stronger than that of clopidogrel with other PPIs $[3,6]$. However, in vivo data show that lansoprazole has the potential to have the same or greater potency than omeprazole. In addition to clinical factors such as drug interactions, genetic factors, including polymorphisms of the CYP system, are important [14, 17]. The CYP2C19 polymorphism in particular appears to play a key role in both clopidogrel and PPI metabolisms. It could be that reduction in the functional alleles of CYP2C19 is associated with lower levels of the active metabolite of clopidogrel, greater levels of platelet reactivity, and a greater rate of adverse clinical outcomes in patients receiving clopidogrel. The COGENT trial is the only available controlled randomized study addressing the clinical relationship between PPIs and clopidogrel, and no evidence of any adverse clinical interaction was reported. However, $94 \%$ of the population in the COGENT trial was Caucasian, and the expected prevalence of CYP2C19 loss-of-function alleles was 2-3\% [3].

The relative risk of gastrointestinal bleeding in patients receiving DAPT and the effectiveness of PPIs in preventing such bleeding are obviously critical to any decision to initiate concomitant therapy with a PPI and clopidogrel. Evidence has shown that PPIs are effective in 
preventing gastrointestinal bleeding in patients receiving antiplatelet therapy, including aspirin or clopidogrel, but the clinical outcomes of various studies have thus far shown conflicting results [3-6].

Therefore, coronary heart disease patients who receive clopidogrel therapy can have different individual responses. We used ADP $20 \mu \mathrm{mol} / \mathrm{L}$ as an inducer and evaluated platelet function by LTA. LTA is the classic method for testing platelet function. In 2010, the POPular study by Breet et al. [26], compared the correlations between incidence of clinical events and six methods of platelet function measurement: VerifyNow ${ }^{\circ}$, LTA, Plateletworks ${ }^{\mathrm{Tm}}$, DiaMed Impact-R, PFA- $100^{\circ}$, and Innovance ${ }^{\circ}$ PFA P2Y. Their results showed that VerifyNow ${ }^{\circ}(13.3 \%$ vs $5.7 \%, P<$ $0.001)$, LTA $(11.7 \%$ vs $6.0 \%, P<0.001)$, and Plateletworks ${ }^{\circ}$ (12.5\% vs 6.1\%, $P=0.005)$ were better correlated with clinical results than the other methods. However, there is still no stronger predictive value than area under the curve $(0.61-0.63)$.

The platelet function test results for individual DAPT is currently a research focus, possibly because on-treatment platelet reactivity is not a modifiable risk factor for thrombotic events after PCI. On the other hand, thrombosis is not only associated with antiplatelet therapy, but also influenced by many environmental and genetic factors, such as atherosclerotic plaque instability; heart, kidney, or other vital organ dysfunction; or sluggish blood flow.

Although in vitro studies have suggested a possible effect and several retrospective analyses were supportive of an adverse clinical outcomes, recent data from prospective controlled trials do not support an adverse cardiovascular outcome, nor do they show a clear relationship between PPI use and adverse outcomes. Therefore, this topic remains controversial. Careful risk-benefit assessment is required before prescribing PPIs to individual patients receiving DAPT, as indicated in the statement by the US Food and Drug Administration.

Safety is a concern in antiplatelet therapy, but in the present study, there were no significant differences between the groups in the rates of muscle pain, liver function test results, gastrointestinal disorders, or incidence of edema or rash during the 30-day and 180-day followup periods.

Our trial had several limitations. Firstly, a major limitation of the study was that CYP2C19 polymorphisms were not considered; therefore, a future study to investigate the influences of concomitant use of clopidogrel with different PPIs in different ethnicities would be necessary. Secondly, the follow-up period was short and the sample relatively small, and so a longer follow-up period and larger sample size will be necessary to explore the effect of PPIs on clopidogrel. Thirdly, we used LTA to test platelet aggregation in our study because of storage time, beside detection just as VerifyNow ${ }^{\bullet}$ may reduce detection error. Finally, as with any prospective study, a causal relation cannot be confirmed, nor can confounding by unknown or unmeasured factors be entirely excluded. Because this was not a blinded study, there was a potential for observational bias.

\section{Conclusion}

In conclusion, the study results suggest that combination therapy with omeprazole or pantoprazole and clopidogrel does not restrict ADP-induced platelet aggregation. There was no apparent association between clinical events and clopidogrel-omeprazole or clopidogrel-pantoprazole combination in NSTE-ACS patients. The clinical impact of this strategy needs to be confirmed by long-term followup outcome studies.

\section{Abbreviations \\ ACS: Acute coronary syndrome; ADP-PA: Adenosine diphosphate-induced platelet aggregation; AEs: Adverse events; CABG: Coronary artery bypass grafting; CYP450: Cytochrome P450; DATP: Dual antiplatelet therapy; LTA: Light transmittance aggregometry; MACE: Major adverse cardiovascular events; NSTE-ACS: Non-ST-segment elevation acute coronary syndrome; PCl: Percutaneous coronary intervention; PPIs: Proton pump inhibitors; TIMI: Thrombolysis in myocardial infarction; TVR: Target-vessel revascularization; UA: Unstable angina}

\section{Acknowledgements}

The authors express sincere thanks to Dr. Ya-Ling Han and all investigators whom involved in this study.

\section{Funding}

This study was supported by National Key Technology R\&D Program in the "Twelfth Five-Year" Plan of China (2011BAl11B07). All the authors planned and contributed to the interpretation of the data, revisions, and inputs at all stages of the study. All the authors have approved the final version of the manuscript.

\section{Availability of data and materials \\ The data and material are available by sending email to guruoxi062514@126.com.}

\section{Authors' contributions}

RXG drafted the manuscript. $J L, J D, X X L$ and JW participated in the design of the study and performed the statistical analysis. XZW conceived of the study, and participated in its design and coordination and helped to draft the manuscript. All authors read and approved the final manuscript.

\section{Competing interests}

The authors declare that they have no competing interests.

Consent for publication

The study was approved for publication by all authors.

\section{Ethics approval and consent to participate}

The study was approved by the ethics committee of General Hospital of Shenyang Military Region.

Received: 22 November 2015 Accepted: 26 November 2016

Published online: 15 December 2016

\section{References}

1. Bhatt DL, Scheiman J, Abraham NS, Antman EM, Chan FK, Furberg CD, et al. ACCF/ACG/AHA 2008 expert consensus document on reducing the gastrointestinal risks of antiplatelet therapy and NSAID use: a report of the American College of Cardiology Foundation Task Force on Clinical Expert Consensus Documents. J Am Coll Cardiol. 2008:52:1502-17. 
2. Tsukahara K, Kimura K, Morita S, Ebina T, Kosuge M, Hibi K, et al. Impact of concomitant use of proton-pump inhibitors and thienopyridine derivatives on the antiplatelet effect. J Cardiol. 2011;57:275-82.

3. Bhatt DL, Cryer BL, Contant CF, Cohen M, Lanas A, Schnitzer TJ, et al. Clopidogrel with or without omeprazole in coronary artery disease. N Engl J Med. 2010;363:1909-17.

4. Simon T, Steg PG, Gilard M, Blanchard D, Bonello L, Hanssen M, et al. Clinical events as a function of proton pump inhibitor use, and cytochrome P450 2C19 genotype in a large nationwide cohort of acute myocardial infarction: results from the French Registry of Acute ST-Elevation and NonST-Elevation Myocardial Infarction (FAST-MI) registry. Circulation. 2011;123:474-82.

5. Abraham NS, Hlatky MA, Antman EM, Bhatt DL, Bjorkman DJ, Clark CB, et al. ACCF/ACG/AHA 2010 Expert Consensus Document on the Concomitant Use of Proton Pump Inhibitors and Thienopyridines: A Focused Update of the ACCF/ACG/AHA 2008 Expert Consensus Document on Reducing the Gastrointestinal Risks of Antiplatelet Therapy and NSAID Use. Am J Gastroenterol. 2010;105(12):2533-49

6. Ho PM, Maddox TM, Wang L, Finn SD, Jesse RL, Peterson ED, et al. Risk of adverse outcomes associated with concomitant use of clopidogrel and proton pump inhibitors following acute coronary syndrome. JAMA. 2009;301:937-44.

7. Juurlink DN, Gomes T, Ko DT, Szmitko PE, Austin PC, Tu JV, et al. A population-based study of the drug interaction between proton pump inhibitors and clopidogrel. CMAJ. 2009;180:713-8.

8. Huang CC, Chen YC, Leu HB, Chen TJ, Lin SJ, Chan WL, et al. Risk of adverse outcomes in Taiwan associated with concomitant use of clopidogrel and proton pump inhibitors in patients who received percutaneous coronary intervention. Am J Cardiol. 2010;105:1705-9.

9. Stockl KM, Le L, Zakharyan A, Harada AS, Solow BK, Addiego JE, et al. Risk of rehospitalization for patients using clopidogrel with a proton pump inhibitor. Arch Intern Med. 2010;170:704-10.

10. Ray WA, Murray KT, Griffin MR, Chung CP, Smalley WE, Hall K, et al. Outcomes with concurrent use of clopidogrel and proton-pump inhibitors: a cohort study. Ann Intern Med. 2010;152:337-45.

11. Dunn SP, Steinhubl SR, Bauer D, Charnigo RJ, Berger PB, Topol EJ, et al. Impact of proton pump inhibitor therapy on the efficacy of clopidogrel in the CAPRIE and CREDO trials. J Am Heart Assoc. 2013;2(1):e004564.

12. Siller-Matula JM, Spiel AO, Lang IM, Kreiner G, Christ G, Jilma B, et al. Effects of pantoprazole and esomeprazole on platelet inhibition by clopidogrel. Am Heart J. 2009;157(1):148.e1-5.

13. Savi P, Pereillo JM, Uzabiaga MF, Combalbert J, Picard C, Maffrand JP, et al. Identification and biological activity of the active metabolite of clopidogrel. Thromb Haemost. 2000;84:891-6.

14. Li XQ, Andersson TB, Ahlström M, Weidolf L. Comparison of inhibitory effects of the proton pump-inhibiting drugs omeprazole, esomeprazole, lansoprazole, pantoprazole, and rabeprazole on human cytochrome P450 activities. Drug Metab Dispos. 2004;32:821-7.

15. Chen $\mathrm{CH}$, Yang JC, Uang YS, Lin CJ. Differential inhibitory effects of proton pump inhibitors on the metabolism and antiplatelet activities of clopidogrel and prasugrel. Biopharm Drug Dispos. 2012;33:278-83.

16. Bovill EG, Terrin ML, Stump DC, Berke AD, Frederick M, Collen D, et al. Hemorrhagic events during therapy with recombinant tissue-type plasminogen activator, heparin, and aspirin for acute myocardial infarction. Results of the Thrombolysis in Myocardial Infarction (TIMI), Phase II Trial. Ann Intern Med. 1991;115:256-65.

17. Lai KC, Lam SK, Chu KM, Wong BC, Hui WM, Hu WH, et al. Lansoprazole for the prevention of recurrences of ulcer complications from long-term lowdose aspirin use. N Engl J Med. 2002;346(26):2033-8.

18. Hollopeter G, Jantzen HM, Vincent D, Li G, England L, Ramakrishnan V, et al. Identification of the platelet ADP receptor targeted by antithrombotic drugs. Nature. 2001;409(6817):202-7.

19. Brandt JT, Close SL, Iturria SJ, Payne CD, Farid NA, Ernest 2nd CS, et al. Common polymorphisms of CYP2C19 and CYP2C9 affect the pharmacokinetic and pharmacodynamic response to clopidogrel but not prasugrel. J Thromb Haemost. 2007;5(12):2429-36.

20. Sibbing D, Morath T, Stegherr J, Braun S, Vogt W, Hadamitzky M, et al. Impact of proton pump inhibitors on the antiplatelet effects of clopidogrel. Thromb Haemost. 2009;101(4):714-9.

21. Kazui M, Nishiya Y, Ishizuka T, Hagihara K, Farid NA, Okazaki O, et al. Identification of the human cytochrome P450 enzymes involved in the two oxidative steps in the bioactivation of clopidogrel to its pharmacologically active metabolite. Drug Metab Dispos. 2010;38(1):92-9.

22. Sangkuhl K, Klein TE, Altman RB. Clopidogrel pathway. Pharmacogenet Genomics. 2010;20(7):463-5.

23. Furuta $T$, Shirai N, Sugimoto M, Nakamura A, Hishida A, Ishizaki T, et al. Influence of CYP2C19 pharmacogenetic polymorphism on proton pump inhibitor-based therapies. Drug Metab Pharmacokinet. 2005;20:153-67.

24 Kwok CS, Loke YK. Meta-analysis: the effects of proton pump inhibitors on cardiovascular events and mortality in patients receiving clopidogrel. Aliment Pharmacol Ther. 2010;31:810-23.

25 Kenngott S, Olze R, Kollmer M, Bottheim H, Laner A, Holinski-Feder E, et al. Clopidogrel and proton pump inhibitor (PPI) interaction: separate intake and a non-omeprazole PPI the solution? Eur J Med Res. 2010;15(5):220-4.

26 Breet NJ, van Werkum JW, Bouman HJ, Kelder JC, Ruven HJ, Bal ET, et al. Comparison of platelet function tests in predicting clinical outcome in patients undergoing coronary stent implantation. JAMA. 2010;303(8):754-62.

\section{Submit your next manuscript to BioMed Central and we will help you at every step:}

- We accept pre-submission inquiries

- Our selector tool helps you to find the most relevant journal

- We provide round the clock customer support

- Convenient online submission

- Thorough peer review

- Inclusion in PubMed and all major indexing services

- Maximum visibility for your research

Submit your manuscript at www.biomedcentral.com/submit
Biomed Central 